\title{
NOTURNAS ÁGUAS MELANCÓLICAS:

\author{
Sobre "Noturno da Mosela", de Manuel Bandeira
}

NOCTURNAL MELANCHOLIC WATERS:

On “Noturno da Mosela”, by Manuel Bandeira

Wilson José FLORES JR. ${ }^{48}$

RESUMO: Sérgio Buarque de Holanda, em "Trajetória de uma poesia", nota que a "imagem do movimento e da queda d'água", marcante nos primeiros poemas de Manuel Bandeira, "sobrevive longamente" a eles, configurando uma imagem "característica" da poética bandeiriana. O crítico argumenta que, "em horas mais sombrias", as águas representam "a própria transitoriedade e a fugacidade da existência", como ocorre, por exemplo, em "Noturno da Mosela". Este é um dos sentidos em jogo no poema e descreve bem uma de suas linhas de força. Mas, para além dele, há todo um conjunto de imagens (algumas inusitadas) que se entrecruzam, chocam-se e combinam-se de modo a construir uma expressão lírica da melancolia em que é ressaltada sua dimensão agressiva (que se impõe no poema sobre a acedia), centrada nas associações que se desenvolvem em torno da água, da noite e do quarto, projeções exteriores de um momento de autorreflexão da subjetividade lírica.

PALAVRAS-CHAVE: Manuel Bandeira; Poesia brasileira moderna; Agua; Noite; Melancolia.

ABSTRACT: In the essay "Trajetória de uma poesia", Sérgio Buarque de Holanda notes that the "image of the movement and the waterfall", constant in the first poems of Bandeira, "survives for a long time" to them, setting an typical image of Banderian poetic. The critic argues that "in the darkest hours", waters represent "the very impermanence and transience of existence", as occurs, for example, in "Noturno da Mosela". But, furthermore, there is a whole set of images (some unusual) that intersect, clash and combine in order to build a lyrical expression of melancholy, especially in its aggressive dimension, focused on the associations around the water, the night and the private room, projections of a moment of lyrical subjectivity's self-reflection.

KEYWORDS: Manuel Bandeira; Brazilian modern poetry; Water; Night; Melancholy.

48 Doutorando (Bolsista CNPq). Programa de Pós-Graduação em Ciência da Literatura. Faculdade de Letras - Universidade Federal do Rio de Janeiro (UFRJ) - Rio de Janeiro - RJ - CEP 21941-917 - Brasil wfloresjr@ufrj.br 
A poesia de Manuel Bandeira, como se sabe, não é monódica. Ao lado dos poemas mais conhecidos, figuram uma série de outros, igualmente importantes, cujos temas, os procedimentos e mesmo a linguagem não se encaixam bem no conjunto que costuma ser selecionado pelos manuais e antologias mais populares. Entre esses "outros”, encontram-se poemas que se afastam da expressão direta e despojada e se avizinham das associações fragmentárias, bem como da profusão de imagens aparentemente díspares próprias do universo onírico, os quais, como afirmam Antonio Candido e Gilda de Mello e Souza na "Introdução" a Estrela da vida inteira (CANDIDO; MELLO E SOUZA, 1993, p.8), parecem

[...] à primeira vista dispensar um núcleo racional e cristalizar-se inteiramente à volta das imagens. Não estamos mais no universo lúdico e de escolha dirigida, na tranquila zona de luz em que o poeta, movendo-se com inigualável segurança, criou alguns dos mais altos poemas de nossa língua. Mas na zona de sombra, no universo onírico e sobretudo plástico, onde as imagens são descoordenadas e as associações inquietantes.

No mesmo texto, os autores apontam “o pungente sentimento de frustração" como uma constante nesses poemas e, mais, como um dos "temas obsessivos" da poesia bandeiriana $^{49}$.

Trata-se, efetivamente, de tema bastante recorrente em Bandeira, sintetizado, algumas vezes, na ideia de que a "vida é traição" ${ }^{\mathbf{5 0}}$. O poeta tende a ver a frustração não apenas como inescapável, mas também como perene, sendo, por assim dizer, uma espécie de "verdade" em última instância da vida ${ }^{\mathbf{5 1}}$.

49 CANDIDO; MELLO E SOUZA, In BANDEIRA, 1993, p.12. Os autores mencionam, como referências dessa "obsessão", "Pneumotórax" (especialmente aquele que é um dos versos mais conhecidos de Bandeira: "A vida inteira que poderia ter sido e que não foi") e a atitude de "refugiar-se de suas derrotas" num mundo imaginário em que lhe fossem possíveis "aquelas ações insignificantes que compõem a rotina de um menino sadio", que é a tônica de "Vou-me embora pra Pasárgada".

50 Cf. "Momento num café", de Estrela da manhã: "Este sabia que a vida é uma agitação feroz e sem finalidade / Que a vida é traição / E saudava a matéria que passava / Liberta para sempre da alma extinta"; e "Mas carada", de Estrela da tarde: "Conheço que a vida / É sonho, ilusão. / Conheço que a vida, / A vida é traição". 
Algumas vezes, o choque indesejável, mas inevitável com a frustração, redunda em Bandeira numa espécie de "sereno conformismo",52. Outras, ao contrário, dá vazão a sentimentos agressivos, aspecto da subjetividade lírica bandeiriana que, na maior parte do tempo, aparece sublimada, quando não angustiantemente reprimida pela delicadeza, pela sutileza e pela insistência, às vezes levemente afetada, em definir-se pelo menor (algo de que o verso de "Testamento", "sou poeta menor, perdoai", talvez seja o exemplo mais eloquente). A agressividade, não poucas vezes, expressa-se na chave de certa aspiração pelo vazio, por uma "morte absoluta",53, ou, para falar com Freud, no desejo de redução das tensões a zero, próprios da pulsão de morte ${ }^{\mathbf{5 4}}$.

Seguindo essa linha, há um comentário altamente sugestivo - e quase surpreendente - de Antônio Olinto reproduzido na edição de 1958 de Poesia e prosa de Manuel Bandeira, da Editora Aguilar (OLINTO, 1958, p.131). Afirma o crítico:

O Satanismo não é propriamente uma glorificação do mal. Atém-se mais a uma região limítrofe em que o sentimento de perda coloca o homem no limiar do desespero. Não é uma presença. É ausência. Como ausência, tende para o lirismo, um lirismo que nada tem de sentimental, porque superou as camadas convencionais das reações humanas. Manuel Bandeira é, sob esse ângulo, um satanista. Seus poemas buscam a noite, a sombra, o perdido, o esperado, o sofrido sem remissão, o que poderia ter sido e não foi, o que deixou um travo de angústia mansa no pensamento. Em $O$ ritmo

51 Sentimento recorrente em Bandeira, expresso, entre outros, nos versos finais de "Soneto inglês no. 2", da Lira dos cinquent'anos: "Morrer sem uma lágrima que a vida / Não vale a pena e a dor de ser vivida".

52 A expressão é de Gilda de Mello e Souza e Antonio Candido. Como exemplo dessa atitude, os autores citam o primeiro dos poemas intitulados "Belo belo", publicado em Lira dos cinquent'anos, apontando o outro, coligido em Belo belo, como o "oposto simétrico do primeiro", "seu avesso amargo e secreto" (CANDIDO; MELLO E SOUZA, In BANDEIRA, 1993, p.13).

53 Apenas como uma referência, considerem-se os versos iniciais de "A morte absoluta", poema de Lira dos cinquent'anos: "Morrer. / Morrer de corpo e de alma. / Completamente." E, no mesmo poema, uma expressão ao mesmo tempo sutil e direta de frustração e desilusão: "Morrer sem deixar porventura uma alma errante... / A caminho do céu? / Mas que céu pode satisfazer teu sonho de céu?".

54 Cf. O eu e o id, In FREUD, 2010, p.9-64; e GREEN, 1988. 
dissoluto, já a poesia de Bandeira surge limpa de escolas, não-literária, remansosamente perturbadora. $\mathrm{O}$ poema adquirira uma voz própria, criara uma linguagem, abrira um caminho novo.

Na sequência desse trecho, Olinto aponta, entre os poemas em que surgem "a sombra", "o perdido", "o sofrido sem remissão,,55, o "Noturno da Mosela":

\section{"Noturno da Mosela"}

A noite... O silêncio...

Se fosse só o silêncio!

Mas esta queda d'água que não para! que não para!

Não é de dentro de mim que ela flui sem piedade? ...

A minha vida foge, foge - e sinto que foge inutilmente!

O silêncio e a estrada ensopada, com dois reflexos intermináveis...

Fumo até não sentir mais que a brasa e a cinza em minha boca.

$\mathrm{O}$ fumo faz mal aos meus pulmões comidos pelas algas.

O fumo é amargo e abjeto. Fumo abençoado, que és amargo e abjeto!

Uma pequenina aranha urde no peitoril da janela a teiazinha levíssima.

Tenho vontade de beijar essa aranhazinha...

No entanto em cada charuto que acendo cuido encontrar o gosto que faz esquecer... Os meus retratos... Os meus livros... O meu crucifixo de marfim... E a noite...

O noturno do título, como se deduz facilmente, alude a uma forma musical de longa tradição no Ocidente que encontrou sua expressão atual no século XIX, por obra do compositor irlandês John Field (cujo valor repousa, principalmente, na precedência), e, sobretudo, de Frédéric Chopin, cuja maestria, expressas em seus conhecidíssimos 21 noturnos, tornou-o senhor inconteste do gênero: uma composição instrumental, ou melhor, pianística, em que o aspecto noturno liga-se ao caráter meditativo e melancólico, frequentemente tranquilo, mas, por vezes, denso e angustiado ${ }^{\mathbf{5 6}}$. Como se pode perceber, essa combinação de melancolia, contemplação e angústia define o tom do poema. Além disso, o título

55 Como se vê por essas rápidas referências, essa dimensão da poesia de Bandeira não passou despercebida aos seus primeiros leitores. No entanto, foram-lhe dedicados apenas comentários, análises pontuais, anotações, nenhum estudo amplo. E, com o tempo, tal dimensão acabou ofuscada pela luminosidade um tanto imperativa dos poemas que se tornaram os mais conhecidos e das vertentes da crítica que a eles se dedicaram. 
é uma evidência do que Antonio Candido e Gilda de Melo e Souza ${ }^{57}$ identificaram como uma "mania musical" que percorre toda a produção do poeta, repleta de acalantos, canções, baladas, cantigas, madrigais, rondós, noturnos etc., algo, por assim dizer, esperado em um poeta que tantas vezes declarou ser a música a arte de sua predileção ${ }^{\mathbf{5 8}}$. De qualquer maneira, se a música é referência fundamental no poema que estamos começando a discutir, salta aos olhos também a força das imagens a compor um quadro lírico altamente plástico.

Já Mosela, por sua vez, é o nome de uma rua e de um bairro de Petrópolis, cidade onde Bandeira veraneava desde $1914^{\mathbf{5 9}}$ e que continuaria a ser um de seus destinos preferidos até o final da vida. O "Noturno" não está datado na maioria das edições, mas algumas trazem o ano de 1921, o mesmo que consta de outros poemas do livro também compostos na Mosela. Entre esses poemas, convém destacar, sobretudo, "A estrada" e "Noite morta", que formam com o "Noturno" uma espécie de tríptico denso de associações e de imagens, como discutiremos adiante.

O poema se inicia no silêncio: o primeiro verso ("A noite... o silêncio") é, sobretudo, uma imagem "muda". Nenhuma referência auditiva é evocada a não ser em negativo. Mas, já no segundo verso, a tranquilidade é comprometida pelo afloramento de uma percepção consciente, expressa como uma reflexão incômoda, frustrante, que é seguida, um tanto abruptamente, pelo som imperativo da torrente de água. A paz do silêncio noturno, a tranquilidade do vazio é rompida pela persistência irritante do barulho da "queda d'água que não para, que não para" e que flui impassível, indiferente e "sem piedade", dissolven-

$56 C f$. BORBA; GRAÇA, 1963, vol.II, p.298. No que concerne a Bandeira, convém lembrar que o compositor francês Claude Debussy também compôs noturnos e que sua música inspirou o poeta em mais de uma ocasião, em particular num dos poemas mais conhecidos de Carnaval.

57 CANDIDO; MELO E SOUZA, In BANDEIRA, 1993, p.10.

58 Apenas como referência, cite-se o Flash autobiográfico de Manuel Bandeira, "narrado" por João Condé (CONDÉ, In BANDEIRA, 1993, p.29).

59 CONDÉ, “Flash biográfico de Manuel Bandeira”, In BANDEIRA, 1993, p.30. 
do, em seu fluxo e do interior do Eu, a sensação fugaz de sossego que o poeta gozou num brevíssimo instante.

Em "Trajetória de uma poesia"60 , Sérgio Buarque de Holanda nota que a "imagem do movimento e da queda d'água", marcante nos primeiros poemas de Bandeira, "sobrevive longamente" a eles, sendo, por isso, uma imagem "característica" da poética bandeiriana. O crítico argumenta que, em algumas ocasiões, a água em movimento "é apenas uma companhia docemente nostálgica para o desencanto do poeta". Nesses casos, torna-se "afável refrigério", consolo, "mensageira da paz e do sossego" "61 Mas, "em horas mais sombrias", representa "a própria transitoriedade e a fugacidade da existência" "62 . Como referência, o crítico menciona o "Noturno da Mosela" e "A estrada":

"A estrada"

Esta estrada onde moro, entre duas voltas do caminho, Interessa mais que uma avenida urbana.

Nas cidades todas as pessoas se parecem.

Todo o mundo é igual. Todo o mundo é toda a gente.

Aqui, não: sente-se bem que cada um traz a sua alma.

Cada criatura é única.

Até os cães.

Estes cães da roça parecem homens de negócios:

Andam sempre preocupados.

E quanta gente vem e vai!

E tudo tem aquele caráter impressivo que faz meditar:

Enterro a pé ou a carrocinha de leite puxada por um bodezinho manhoso.

Nem falta o murmúrio da água, para sugerir, pela voz dos símbolos,

Que a vida passa! Que a vida passa!

E a mocidade vai acabar.

60 HOLANDA, 1978, p.29-44.

61 É o caso, por exemplo, de "Murmúrio d'água". Apenas como referência, considerem-se os versos: "Água de fonte... água de oceano... água de pranto... / Água de rio... / Água da chuva, água cantante das lavadas... / Têm para mim, todas, consolos de acalanto / A que sorrio...”; “- Murmúrio d'água, és a cantiga de minh'ama." (BANDEIRA, 1993, p.108).

62 HOLANDA, 1978, p.34. 
Petrópolis, 1921

As relações entre "A estrada" e o "Noturno", como se pode observar, expressam-se não apenas pelas imagens mobilizadas por ambos (a noite, a queda d'água, a estrada), como também pela atmosfera lírica, basicamente a mesma nos dois poemas. Essa identidade de fundo explica-se, em parte, pelo fato de ambos terem sido escritos quase ao mesmo tempo em Petrópolis, cuja “atmosfera” Bandeira, no Itinerário de Pasárgada (BANDEIRA, 1966, p.76), afirma ser uma das "influências" mais importantes em O ritmo dissoluto:

Às influências assinaladas anteriormente há que acrescentar essa da atmosfera de Petrópolis. Dos vinte e quatro poemas que perfazem $O$ Ritmo Dissoluto, oito foram escritos na Mosela. Mas a ação de Petrópolis só se exerce quando estou lá, ação lenitiva, que atuando sobre a minha sensibilidade, logo me comunica aos versos um manso ritmo de aceitação.

Bandeira não costuma ser o melhor intérprete de si mesmo, como ocorre, aliás, com qualquer pessoa, seja ela poeta, filósofo ou psicanalista ${ }^{63}$. Difícil reconhecer nos poemas que estamos discutindo o "manso ritmo de aceitação" a que ele se refere no trecho do Itinerário. Nos versos: "Que não para! Que não para”; "Minha vida foge, foge e sinto que foge inutilmente"; "Que a vida passa! Que a vida passa!”; as repetições enfáticas não sugerem mansidão, nem aceitação. Ao contrário, indicam frustração, mal-estar e uma ponta de revolta. As ideias de a vida fugir e da inutilidade da existência vão na mesma direção.

De qualquer maneira, em "A estrada" a atitude é, digamos, mais mansa do que no "Noturno", mas, ainda assim, a "ação lenitiva" de Petrópolis parece atuar mais na chave de diminuir a agitação ao redor, centrar o poeta em si e, assim, permitir -lhe entrar em contato com aspectos de sua subjetividade normalmente ofuscados pelas atividades rotineiras e pela relativa agitação do Rio de Janeiro ${ }^{64}$. O lirismo de ambos os poemas sugere certo estado de

63 É fato mais ou menos consensual que nenhum indivíduo tem plena consciência de si, nem dos sentidos efetivos das coisas que o movimentam ou dos efeitos que elas têm sobre ele, afinal, para citar uma frase de Freud bastante conhecida, "o ego não é senhor em sua própria casa".

64 Além da comparação feita nos versos iniciais entre "a estrada" e "uma avenida urbana", Bandeira várias vezes mencionou (principalmente nas crônicas e em sua correspondência) o desconforto que sentia diante do trânsito, das modificações urbanas, da multidão crescente que ele sentia dominarem cada vez mais a cidade do Rio de Janeiro. 
repouso reflexivo (o "caráter impressivo que faz meditar"), mas não é conforto, alívio ou consolação o que resulta disso, senão uma atmosfera melancólica que depara as dimensões "diabólicas" do sujeito, aquelas associadas a certo flerte com o vazio, em que a agressividade (submetida a uma intensa elaboração no poema) faz transparecer a insatisfação com o mundo, com os outros (algo que a percepção estrangeira de Petrópolis, típica de visitante ou de um viajante de passagem, confirma, uma vez que ela só adquire sentido pleno sobre o pano de fundo do Rio de Janeiro) e consigo mesmo ${ }^{65}$. Não é por acaso que os poemas evoquem tão profundamente a solidão.

Seguindo essa mesma linha, e, como já foi sugerido, formando uma espécie de tríptico (na medida em que a plasticidade é bastante forte nos três) com os outros dois poemas, há "Noite morta", outro dos poemas escritos na Mosela:

"Noite morta"

Noite morta.

Junto ao poste de iluminação

Os sapos engolem mosquitos.

Ninguém passa na estrada.

Nem um bêbado.

No entanto há seguramente por ela uma procissão de sombras.

Sombras de todos os que passaram.

Os que ainda vivem e os que já morreram.

O córrego chora.

A voz da noite...

(Não desta noite, mas de outra maior.)

Petrópolis, 1921

65 Bandeira várias vezes referiu-se à sua poesia como uma espécie de resultado do "fracasso" de sua vida. Os poemas "Testamento", da Lira dos cinquent'anos, e "Auto-retrato", de Mafuá do malungo", são os exemplos mais conhecidos. Além deles, considerem-se como referência duas passagens da crônica "Homenagem a MB", de Andorinha, andorinha (BANDEIRA, 1997, p.222-223): “/../ no fracasso de minha vida e na expressão poética desse fracasso /.../" ; "Orgulhoso dos estudos críticos de Afonso Arinos de Melo Franco, cujo trabalho deveria intitular-se não "Manuel Bandeira ou o Homem contra a Poesia" e sim 'Manuel Bandeira ou o Poeta contra o Homem". 
"Noite morta", sem dúvida, demandaria uma análise detida. Mas, para os limites deste estudo, enfatizaremos apenas alguns aspectos do poema, visando o diálogo com "Notuno da Mosela". No Itinerário de Pasárgada (BANDEIRA, 1966, p.76), Bandeira afirma que "Noite morta" é

[...] um dos meus prediletos em toda a minha obra, não sei se porque até hoje guardou para mim a atmosfera do lugar e do momento em que. o escrevi, ou se porque, embora em versos-livres, o sinto, na forma, bem mais necessariamente inalterável do que os meus poemas de metro cuidadosamente construído.

Entre os aspectos formais mais significativos pode-se destacar a sonoridade, centrada em variações em torno da vogal "O" (todos os versos oferecem exemplos: nOite mÓrta, sapOs engÓlem mOsquitos, prociss $\tilde{A} O$ de sOmbras, cÓrrego chÓra, entre outros).

No campo das imagens, a estrada vazia, mas repleta de "sombras" de todos os que por ela passaram, cria uma espécie de equivalência entre "os que ainda vivem" e "os que já morreram", como se as fronteiras entre vida e morte evanescessem, colaborando para construir o ambiente nebuloso, onírico ou mesmo fantástico em que se misturam realidade e sonho, referências materiais e "sobrenaturais", que encontram uma síntese nos dois últimos versos, nos quais surge a "voz da noite", "não desta noite, mas de outra maior".

Observe-se que nesses versos há uma sequência caracterizada pela permanência do som da vogal "O", cuja sustentação torna-o mais expandido, mais distante, mais imaterial ("A vOz da nOite... / NãO desta nOite, mas de Outra maiOr"), espelhando, no campo sonoro, aquilo mesmo que se enuncia: da noite como "fato observável" em direção à noite como expressão do mistério profundo do não-ser.

No campo das imagens, note-se que o verso "o córrego chora" produz efeito semelhante ao da queda d'água do "Noturno da Mosela", e do "murmúrio d'água", de "A estrada", todos associados à fugacidade angustiante (e sem finalidade) da vida.

Nesse aspecto, retomando especificamente o "Noturno", observe-se que nele há outras duas imagens igualmente associadas à água: "estrada ensopada" e "pulmões comidos pelas algas". Nesses casos, ao invés de fluida, as águas estão paradas, empoçadas. Aqui a referência não é o fluxo do tempo, mas o obstáculo, a persistência de algo incômodo que 
"ensopa", encharca, infiltra-se, empapa, corrói.

A imagem do "pulmão comido pelas algas”, aliás, guarda relação (mediada pela lírica, pela tradição literária etc.) com o longo período que Bandeira conviveu com a tuberculose: já na Antiguidade Clássica, a partir da teoria dos quatro elementos e dos humores, Hipócrates definia as doenças pulmonares como doenças da água ${ }^{\mathbf{6 6}}$. Isso porque a falta de ar e a dificuldade de respirar é resultado da profusão de secreções e fluidos, produzindo no doente uma sensação semelhante à de um afogamento, que, no caso do poema de Bandeira, surge como um "ataque" realizado pelas algas. Nesse sentido, a associação em torno da água é alterada: deixa de evocar o tempo que passa para ligar-se diretamente à morte ${ }^{67}$ no que ela carrega de paralisante, esterilizante, mutilador, e não no que tem de silêncio, de quietude, de esvanecimento de tensões, associações complementares e ambivalentes com que a morte ameaça e seduz o Eu lírico ${ }^{68}$.

Além disso, é em face dessas águas deletérias que o fumo surge no poema como abençoado e abjeto. $\mathrm{O}$ ar intoxicante do fumo é um substituto degradado do ar puro que, invadindo os pulmões, livraria o Eu da doença, mas, ainda assim, é uma bênção, na medida em que, pela via do negativo, do abjeto, instiga e provoca o que está ensopado e paralisado. $\mathrm{O}$ ato de fumar produz um mal, digamos, ativo como resposta a um mal passivo (fruto da

66 Cf. PIGEAUD, 2009. Em particular o capítulo "O humor dos Antigos" (p.53-80).

67 As associações água-noite / umidade-morte, envoltas por uma intensa aura de atração (muitas vezes erótica, na medida em que aprofunda as relações de água e noite com o feminino) é central em outro poema de $O$ ritmo dissoluto, "Na solidão das noites úmidas": "Como tenho pensado em ti na solidão das noites úmidas, / De névoa úmida, / Na areia úmida! / [...] / O mar... Onde se via o movimento da água, / Era como se a água estremecesse em mil sorrisos. / Como uma carne de mulher sob carícia. / O luar era um afago tão suave, / Tão imaterial - / E ao mesmo tempo tão voluptuoso e tão grave! / O luar era a minha inefável carícia: / A água era teu corpo a estremecer-se em delícia. / [...] / Oh, viver contigo! / Viver contigo todos os instantes... / Vi vermos junto, como seria viver a verdadeira vida, / Harmoniosa e pura, / Sem lastimar a fuga irreparável dos anos, / Dos anos lentos e monótonos que passam, / Esperando sempre que maior ventura / Viesse um dia no beijo infinito da mesma morte..." (BANDEIRA, 1993, p.107).

68 A associação água-morte é recorrente em vários poemas ao longo de toda a produção de Bandeira, como é o caso de "Boi morto", poema escrito 34 anos depois do "Noturno da Mosela", em 1955. Mas nele a morte não surge como ameaça de paralisia ou promessa de quietude; ao contrário - e paradoxalmente - associa-se a movimento intenso, agônico, como se todas as forças da ira, da agressividade e da angústia se combinassem na enchente que arrasta o boi. 
"ação" das algas) que condenaria o sujeito à acedia e à impotência. Tais referências formam um conjunto em que reponta boa dose de autoironia e de sarcasmo sutil ( $2^{\mathrm{a}}$ estrofe e os dois versos seguintes, ligados à "aranhazinha"), antecedidos ( $1^{\mathrm{a}}$ estrofe e verso seguinte) e seguidos (última estrofe) de um mergulho íntimo de fundo melancólico.

Observe-se ainda que o fumo encerra em si uma referência melancólica: solitário; remédio e doença ao mesmo tempo; esperança de vida (prefigurada na "brasa") e garantia de morte (a "cinza"); amargo, abjeto e abençoado - melancolia elaborada e bastante diversa do "gosto cabotino da tristeza". Por meio da autoironia, os percalços enfrentados pelo Eu são relativizados ${ }^{69}$. A ironia, por certo, não "cura", mas diminui a ênfase, afasta (ou pelo menos minimiza) a autolamentação vazia, a subjetividade patética, deslocando a ênfase (ainda que nunca definitivamente, pois as duas dimensões conviverão até o fim) na direção de um humor ferino muito próprio a Bandeira, frequentemente ligado à expressão do degradado, do ruinoso, num procedimento que é o negativo da atitude de aceitação e de "sereno conformismo", característica de vários dos poemas mais conhecidos de Bandeira.

A outra imagem associada às águas putrefatas é a da "estrada ensopada", em que se projetam “dois reflexos intermináveis". Os reflexos se alongam e se distorcem a ponto de parecerem intermináveis estabelecendo um claro contraponto à ideia de que a vida foge. Em contraste com a rapidez e com a brevidade indomável da existência, as imagens refletidas insistem em durar, sugerindo a sensação de um tempo em "marcha lenta", dominado pela repetição infinita do mesmo, outra das faces da acedia (bem como da prostração e do cuidado imperativos necessários para enfrentar a doença). Além disso, evoca novamente a pulsão de morte com que o poeta, digamos, traquinamente, parece fletar, num jogo de recusa e aproximação. Esse, aliás, é um dos gozos que se percebe nos versos: há um jogo que mistura o gosto um tanto travesso e erótico de aproximar-se e tocar o "proibido", o arriscado, como que colhendo o prazer de, ainda que precariamente, sentir-se sujeito da situação, senhor roto e débil de si, dos próprios "fantasmas", da vida e da morte.

69 Um dos pontos mais altos da ironia bandeiriana é o poema "Antologia", de Estrela da tarde. Ao invés de uma autocontemplação satisfeita e deslumbrada ou de uma modéstia afetada, em "Antologia" Bandeira olha para a própria obra com lucidez e bom-humor, como que sugerindo que tudo o que tinha de importante a dizer estaria sintetizado naqueles versos que ele pinçou de poemas escritos em diferentes momentos de sua produção. O procedimento de reduzir a obra a fragmentos, a partir dos quais o poeta remonta uma construção que enfatiza o contingente, o ruinoso é central no poema. Quanta diferença há entre a autoironia fina de "Antolo gia" e a autocomiseração um tanto afetada de "Testamento", da Lira dos cinquent'anos. 
Outro aspecto relevante desse verso é que se trata de "reflexos" e não de objetos (materialidade que a queda d'água evoca), configurando uma espécie de realidade de "segunda mão", uma espécie de miragem, como as sombras de "Noite morta". As sensações de concretude e imaterialidade convivem lado a lado, conferindo ao poema um tom, ao mesmo tempo, familiar e estranho, sustentado pelas demais imagens, como no jogo entre a presença espectral da aranhazinha, a concretude simples e direta dos objetos (retratos, livros, crucifixo de marfim) e a presença ubíqua da noite, ao mesmo tempo "real" (está escuro, talvez seja madrugada) e "transcendente" (a noite como presença sensível que se mantém para além das aparências em associações com a solidão, o inconsciente e a morte).

De qualquer forma, a transcendência em questão opera na chave da imaterialidade de sentimentos, desejos, frustrações e angústias imanentes (associadas à constituição mesma do sujeito lírico, ao seu inconsciente) e não do vislumbre de qualquer salvação (ou condenação) divina, religiosa ou espiritual. O poema não oferece conforto ou consolação, se por isso se entender algum tipo de sentido para a fugacidade e, no limite, para o absurdo da existência. O gozo que se observa nos versos vem não de qualquer consolo, mas do fascínio que a pulsão de morte exerce sobre o Eu e que se expressa na aspiração pelo vazio, bem como no charuto, no qual o eu lírico imagina encontrar "o gosto que faz esquecer", que entorpece a consciência e, ainda que imperfeitamente, aproxima-o da "redução das tensões a zero”, própria do inorgânico, do não-ser, espécie de resposta precária, irônica e possível às frustrações ineludíveis da vida ${ }^{70}$.

É em função do reconhecimento, ao mesmo tempo tranquilo e perplexo, da inutilidade e da falta de finalidade da vida, bem como do desamparo e da inescapável solidão com que se está destinado a confrontar vários dos maiores desafios e aflições da existência, que a imagem da aranha pode ser interpretada. A "aranhazinha" e sua "teiazinha levíssima" são marcadas, linguisticamente, pelos diminutivos e pelo superlativo, ambos colaborando para construir a ideia de fragilidade, de algo ao mesmo tempo admirável e precário. Ao tecer, a aranha evoca para o poeta a fragilidade das construções de sentido em

70 A esse respeito, vale recordar a última estrofe da "Oração a Nossa Senhora da Boa Morte", poema de 1931 reunido em Estrela da manhã: "Fui despachado de mãos vazias! / Dei volta ao mundo, tentei a sorte. / Nem alegrias mais peço agora, / Que sei o avesso das alegrias. / Tudo que viesse, viria tarde! / O que na vida procurei sempre, / - Meus impossíveis de Santa Rita - / Dar-me-eis um dia, não é verdade? / Nossa Senhora da Boa Morte!" 
que o poeta procura se agarrar e, ao mesmo tempo, impõe-se como imagem da persistência e da criação contra todas as probabilidades, despertando no Eu uma atitude que condensa atração, condescendência (uma vez que o poeta, por um momento, parece ter uma percepção da realidade que ultrapassa aquela que faria a aranha continuar a tecer), e profunda identificação, afinal, o poeta não está a se dedicar, ele mesmo, a tecer a trama levíssima de seu poema enquanto observa e reflete sobre a íntima e micrológica cena que se desenvolve em seu quarto?

Assim, a imagem da aranhazinha condensa outra ambivalência decisiva no poema: a consciência, a sensibilidade, a inteligência e o potencial criativo são, ao mesmo tempo, o pequeno bastião em que o poeta se agarra e o fardo insuportável do qual deseja se livrar ${ }^{71}$.

O último verso, ao retomar o primeiro, sugere que a vida é apenas um intermezzo barulhento, "uma agitação feroz e sem finalidade"72 entre dois silêncios que parecem situarse fora do tempo, no ponto focal de onde tudo veio e para onde tudo vai - e, em certa medida, quer - voltar.

\section{REFERÊNCIAS}

BANDEIRA, M. Estrela da vida inteira. 25.ed. Rio de Janeiro: Nova Fronteira, 1993. Itinerário de Pasárgada. 3.ed. Rio de Janeiro: Ed. do Autor, 1966. Poesia e prosa. Rio de Janeiro: José Aguilar, 1958. . Seleta de prosa. Rio de Janeiro: Nova Fronteira, 1997.

BORBA, T.; GRAÇA, F. L. Dicionário de música. Lisboa: Edições Cosmos; Rio de Janeiro: Livraria Luso-Espanhola e Brasileira, 1963. (2 vols.)

CANDIDO, A.; MELLO E SOUZA, G. Introdução. In: BANDEIRA, M. Estrela da vida inteira. 25.ed. Rio de Janeiro: Nova Fronteira, 1993. p.3-17.

FREUD, S. O eu e o id, "autobiografia" e outros textos: 1923-1925. São Paulo: Companhia das Letras, 2010. (Obras completas, vol.16; tradução de Paulo César de Souza).

71 Essa vontade de se livrar do fardo da razão/consciência, aliás, reponta em vários momentos da produção de Bandeira. Provavelmente, o caso mais direto é a "Canção do suicida", de Estrela da tarde: "Não me matarei, meus amigos. / Não o farei, possivelmente. / Mas que tenho vontade, tenho. / Tenho, e, muito curiosamente, // Com um tiro. Um tiro no ouvido, / Vingança contra a condição / Humana, ai de nós! sobre-humana / De ser dotado de razão".

72 Trecho de um verso do poema "Momento num café", de Estrela da manhã. 